\title{
MENGENAL ERGONOMI KERJA YANG BAIK SAAT BERAKTIVITAS DI KANTOR
}

\author{
Adi Saputra Junaidi ${ }^{1)}$, Attika Ayu Putri Mayang Sari ${ }^{2)}$. \\ ${ }^{1,2)}$ PRODI D III Fisioterapi STIKes Baiturrahim Jambi \\ Email: adi_saputrajunaidi@yahoo.co.id
}

\begin{abstract}
Ergonomics is one of the functions in increasing productivity in the form of rules in work that intends to make the working safe system, healthy, safe and comfortable. The incompatibility of ergonomic factors will result in errors in the work posture and generally accompanied by musculoskeletal symptoms in the form of pain. Ergonomics of work posisition in work is very important, if the work posisition is contrary to the body's natural will cause fatigue and injury to the muscles. The method or implementation of community service is in the form of percentage of power points, leaflets, banners, and education and simulation. The conclusion is an understanding of the importance of ergonomic positions when working along with stretching actions or movements that must be done at rest and the ideal resting time when working or doing activitie
\end{abstract}

Keywords: Ergonomics, worker at the office

\begin{abstract}
ABSTRAK
Ergonomi merupakan salah satu fungsi dalam meningkatkan produktivitas berupa aturan dalam bekerja yang bermaksud membuat sistem kerja selamat, sehat, aman dan nyaman. Ketidak sesuaian faktor ergonomi akan mengakibatkan kesalahan dalam postur kerja dan umumnya disertai gejala muskuloskeletal disorder berupa rasa nyeri. Ergonomi sikap kerja dalam bekerja sangat perlu diperhatikan, jika sikap kerja bertentangan dengan sikap alami tubuh akan menimbulkan kelelahan dan cedera pada otot. Sasaran pengabdian masyarakat ini adalah pegawai kantor camat kecamaan Kota Baru. Metode atau pelaksanaan Pengabdian masyarakat ini berupa, persentasi/edukasi dengan menggunakan power point, leaflet, spanduk, dan simulasi. Simpulan adanya pemahaman tentang pentingnya posisi yg ergonomi pada saat beraktivitas atau bekerja beserta tindakan atau gerakan penguluran yang harus dilakukan pada waktu beristirahat dan waktu jeda yang ideal pada saat waktu bekerja atau beraktivitas.
\end{abstract}

Kata Kunci: Ergonomi , pekerja kantor

\section{PENDAHULUAN}

Sehat adalah keadaan sejahtera secara fisik, mental dan sosial yang merupakan satu kesatuan, bukan hanya terbebas dari penyakit maupun cacat. Sejalan dengan definisi sehat menurut WHO, menurut undang-undang kesehatan no. 36 tahun 2009 sehat adalah keadaan sejahtera dari badan, jiwa, dan sosial sehingga memungkinkan setiap orang dapat hidup produktif secara sosial dan ekonomi. Hal ini berarti kesehatan seseorang berperan penting untuk menunjang produktifitas orang tersebut dalam hidupnya. Kesehatan dan keselamatan kerja merupakan bagian yang penting dalam pekerjaan. Oleh karena itu, undang-undang nomor 36tahun 2009 tentang kesehatan dibentuk dengan tujuan untuk mengatur ketenangan kesehatan dan keselamatan bagi setiap indifidu termasuk para pekerja.

Pada kenyataannya banyak masalah kesehatan yang terjadi akibat ketidak waspadaan tenaga kerja akan bahaya potensial kerja yang terdapat pada 
lingkungan kerja termasuk perkantoran. Bahaya potensial kerja dapat berupa bahaya biologi, kimia, fisik dan ergonomi.

Ergonomi merupakan salah satu fungsi dalam meningkatkan produktivitas berupa aturan dalam bekerja yang bermaksud membuat sistem kerja selamat, sehat, aman dan nyaman. Ergonomi menjamin manusia bekerja sesuai dengan kemampuan, kebolehan dan keterbatasan yang hasil akhirnya manusia mampu berproduksi lebih optimal selama umur produktivnya tanpa harus mengorbankan keselamatan dan kesehatannya. Ketidak sesuaian faktor ergonomi akan mengakibatkan kesalahan dalam postur kerja dan umumnya disertai gejala muskuloskeletal disorder berupa rasa nyeri.

Kejadian muskuloskeletal disorder menjadi salah satu alasan utama pekerja untuk absen dari pekerjaan dan mengakibatkn kerugian bagi institusi yang memperkerjakan baik kerugian waktu, pelayanan, maupun materi. Ergonomi sikap kerja dalam bekerja sangat perlu diperhatikan, jika sikap kerja bertentangan dengan sikap alami tubuh akan menimbulkan kelelahan dan cedera pada otot. Dalam sikap yang tidak alami tersebut akan banyak terjadi pergerakan otot yang tidak seharusnya terjadi sehingga gerakan itu akan boros energi yang menimbulkan strain dan cedera otot. Maka dari itu peran fisioterapi dalam untuk menyampaikan atau mengedukasi kepada pekerja kantor supaya terhindar dari cidera atau kelelahan yang tidak berarti pada saat beraktivitas dikantor.

Fisioterapi adalah bentuk pelayanan kesehatan yang ditujukan kepada individu dan atau kelompok untuk mengembangkan, memelihara, dan memulihkan gerak dan fungsi tubuh sepanjang daur kehidupan dengan menggunakan penanganan secara manual, peningkatan gerak, peralatan (fisik, elektroterapeutik, mekanik), pelatihan fungsi komunikasi.

\section{TARGET DAN LUARAN}

1. Terjadi peningkatan pekerja yang sehat

2. Peserta mampu menjawab pertanyaan terkait ergonomic yang baik

3. Peserta mampu menstimulasikan posisi ergonomi yang baik saat bekerja

4. Peserta mampu melakukan peregangan dan penguluran untuk mecegah kekakuan otot

5. Efektifitas dan efisiensi penggunaan fasilitas dan sumber dana

\section{METODE PELAKSANAAN}

Materi kegiatan yang dikembangkan berupa, power point, leaflet, spanduk, serta edukasi dan simulasi. Materi power point dan leaflet untuk penyuluhan dibuat semenarik mungkin, menggunakan gambar dan kalimat yang sederhana sehingga mudah dimengerti oleh sasaran, dilakukan dengan teknik wawancara dan observasi langsung kepada sasaran. Tim pengabdian menyampaikan materi dan praktik kepada peserta, refleksi dan umpan balik dari peserta kegiatan berupa pertanyaan langsung ataupun keluhan yang dialami.

\section{HASIL DAN PEMBAHASAN}

1. Populasi pada pengabdian masyarakat ini merupakan pegawai kantor camat Kota Baru Jambi yang dihadiri 40 orang pegawai kantor baik laki-laki ataupun perempuan didapatkan berdasarkan jumlah absensi peserta yang hadir.

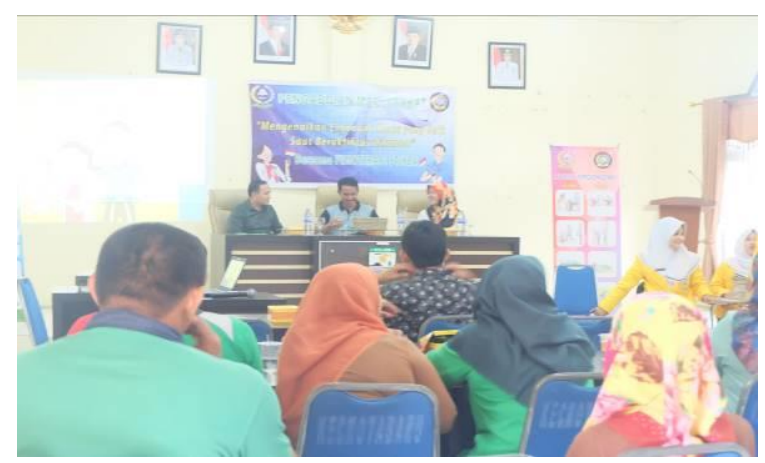




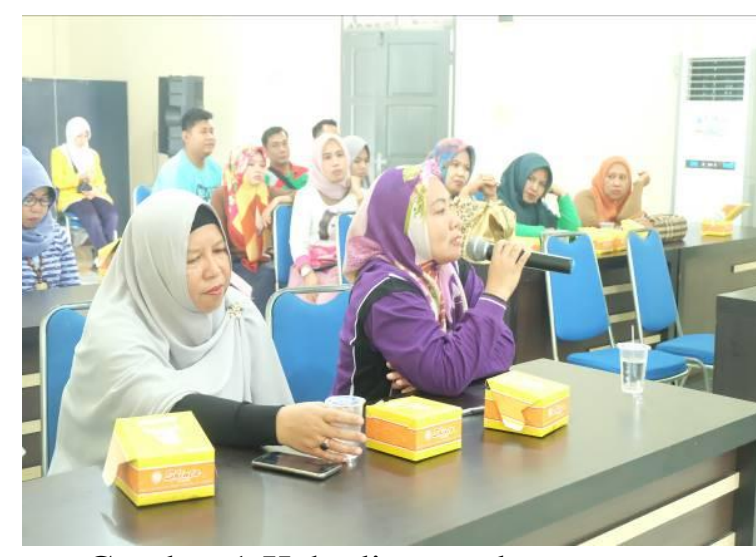

Gambar.1 Kehadiran pada saat acara

2. Pengabdian yang dilakukan berbentuk berupa modul, power point, leaflet, spanduk, serta edukasi dan simulasi.
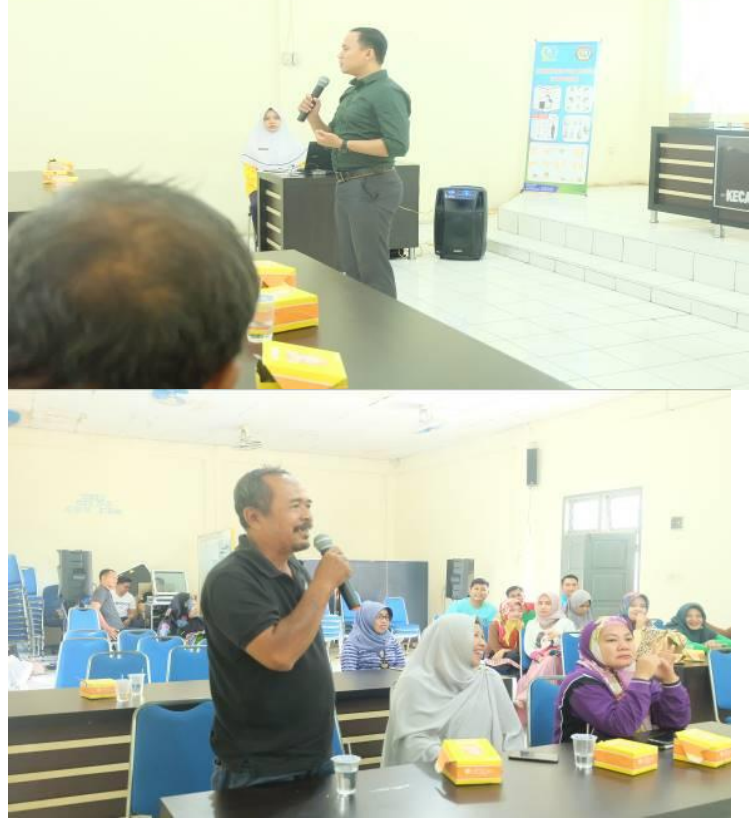

Gambar. 2 Persentasi dan Edukasi Kepada Pekerja

3. Untuk mengetahui keluhan dan permasalahan pada pekerja dilakukan assesment atau pemeriksaan postur dan fungsi tubuh pada saat bergerak ataupun diam dankemudian diberikan tindakan fisioterapi bagi petugas kantor yang mengalmi masalah pada postur dan kelainan otot baik nyeri, kekakuan ataupun ketidakmampuan fungsi pada saat beraktifitas dikantor.

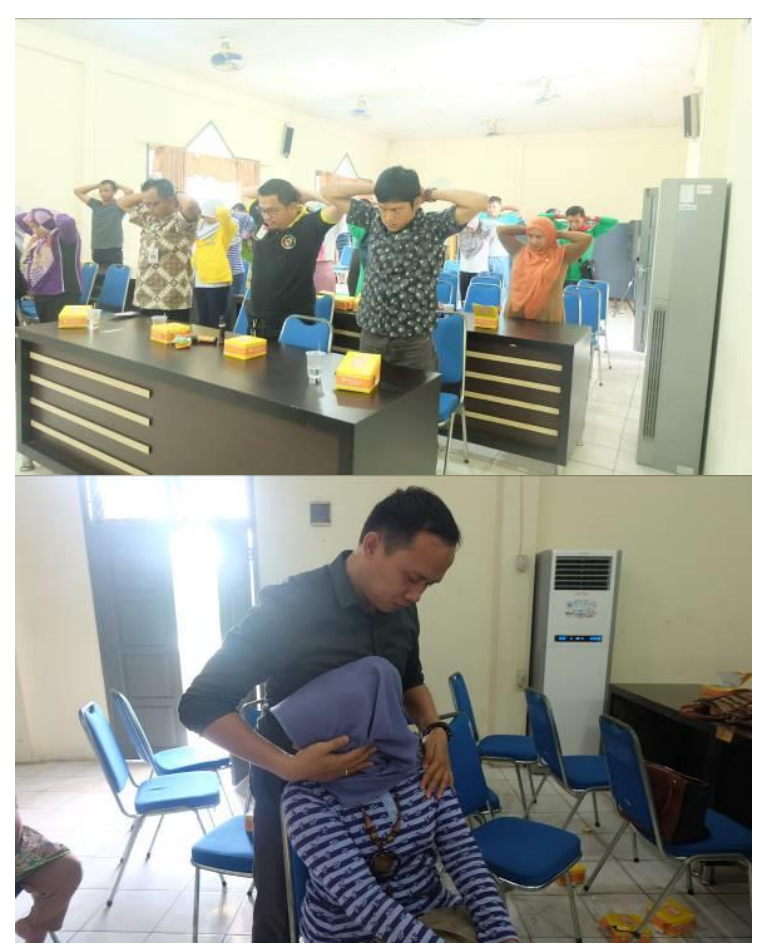

Gambar. 3 Assesmen dan tindakan

Fisioterapi beserta yang harus dilakukan pada saat bekerja

\section{KESIMPULAN DAN SARAN}

\section{Kesimpulan}

Dampak yang direncanakan dari hasil program (intended effect) adalah perubahan perilaku, meningkatnya penerapan ergonomi yang baik di lingkungan kerja kantor, terciptanya pekerja yang sehat, berkualitas dan produktif.

\section{Saran}

Saran agar terhindar dari ergonimi yang buruk dan permasalahan nyeri otot, sendi ataupun tulang sebaiknya selalu memperhatikan posisi pada saat beraktifitas ataupun posisi alat kerja yang digunakan beserta lakukan penguluran otot dan peregangan pada setiap sendi minimal 30 menit berselang pada saat beraktivitas baik statis atupun aktivitas yang dinamis.

\section{UCAPAN TERIMAKASIH}

Terutama kami ucapkan terimaksih kepada Ketua STIKes Baiturrahim Jambi 
yang telah memberikan izin dan mensuport pendanaan atau biaya yang dibutuhkan dalam kegiatan tersebut dan juga kami ucapkan terimakasih kepada seluruh jajaran pegawai kantor Kecamatan Kota Baru, Jambi yang telah berpartisipasi dalam kegiatan ini seterusnya kami ucapkan terimaksih kepada Bapak camat kota baru yang telah memberikan izin dalam penyuluhan ini dan terimakasih juga kami ucapkan kepada semua tim pengabdian masyaraakat yang terkait.

\section{DAFTAR PUSTAKA}

Arfiasari, agustin dwi. 2014. Hubungan Postur Kerja Dengan Keluhan Muskuluskeletal Dan Produktivitas Kerja Pada Pekerja Bagian Pengepakan Di Pt. Djitoe Indonesia Tobako.

Cohen, alexander, 1. Et.al. Element of ergonomics programs. A primer based o workplace evaluation of musculoskeletal disorders.
Amerika : u.s. departement of health and human service. Niosh 1997

Nurliah aah. 2012. Analisis risiko musculoskeletal disorders pada operator forklift di pt lli tahun 2012.

Putera, Adi. Diakses pada 14 Agustus 2017 . Ergonomi merupakan salah satu wahana dalam meningkatkan produktifitas.

http://www.ergoweb.com/news/Sub scribeNewsletter.cfm

Breckling, J., 2012. The analysis of directional time series: applications to wind speed and direction (Vol. 61). Springer Science \& Business Media.

Sang Asni, Djakakusli Rafael, Resseng Syamsiar s. 2013. Hubungan risiko postur kerja dengan keluhan musculoskeletal disorders (msds). 